\title{
INTEGRALISMO LUSITANO E EDUCAÇÃO CATÓLICA: CONEXÕES ENTRE INTELECTUAIS E O CASO DO COLÉGIO VASCO DA GAMA DE LISBOA, PORTUGAL (DÉCADA DE 1920)
}

\author{
DOI: http://dx.doi.org/10.1590/2236-3459/71181
}

\author{
Mauro Castilho Gonçalves \\ Pontifícia Universidade Católica de São Paulo (PUC/SP), Brasil \\ Universidade de Taubaté (Unitau), Brasil
}

$\cos 8$

\begin{abstract}
Resumo
O artigo examina o projeto cultural e pedagógico do colégio lisboeta Vasco da Gama, instituição de ensino fundada em 1915, que pretendeu instruir e educar seus alunos sob as bases da educação física, da religião e das artes, à luz da doutrina católica, dos princípios integralistas e de uma rígida disciplina interna. Um periódico criado em meados dos anos de 1920, fonte central da investigação, serviu de esteio para configurar o projeto cultural do colégio e expressar de forma institucional uma rede de sujeitos conectados e ativos em tempos conturbados da política portuguesa. Fundamentado na história dos intelectuais e do político, o estudo, por fim, analisa conexões entre o integralismo lusitano e o nacionalismo católico brasileiro.

Palavras-chave: intelectuais, educação católica, integralismo lusitano.
\end{abstract}

\section{LUSITANIAN INTEGRALISM AND CATHOLIC EDUCATION: CONNECTIONS BETWEEN INTELLECTUALS AND VASCO DA GAMA COLLEGE'S CASE IN LISBOA, PORTUGAL (IN 20'S)}

\begin{abstract}
Article examines cultural and pedagogic project of Vasco da Gama's College, educational institution that intended to instruct and educate its students based on physical education, religion and Arts, in light of catholic doctrine, integralist principles and a rigid internal discipline. A journal created in 20's, main source of investigation, served as mainstay to set up a cultural project and bring a network of connected and active individuals in turbulent times of Portuguese Politics. Well-founded on intellectual history and politicians, the study finally, analyses connections between Lusitanian Integralism and a Brazilian Catholic Nationalism. Keywords: intellectuals, catholic education, lusitanian integralism.
\end{abstract}

\section{INTEGRALISMO LUSITANO Y LA EDUCACIÓN CATÓLICA: CONEXIONES ENTRE LOS INTELECTUALES Y EL CASO DEL COLEGIO VASCO DA GAMA, PORTUGAL (DÉCADA DE 1920)}

\section{Resumen}

El artículo examina el proyecto cultural y pedagógico del Colegio Vasco de Gama, institución de enseñanza que instruían a sus estudiantes basados en la educación física, la religión y las Artes, a la luz de la doctrina católica y con principios integralistas y una disciplina rígida interna. Un periodico (1920) sirvió como soporte principal para establecer un proyecto cultural del Colegio y expresar de manera institucional una red de individuos conectados y activos en la política portuguesa en tiempos de turbulación. Basado en la historia 
intelectual y política, el estudio analiza la conexión entre el integralismo lusitano y el nacionalismo católico brasileño.

Palabras clave: intelectuales, educación católica, integralismo lusitano.

\section{INTEGRALISME LUSITANIEN ET L'EDUCATION CATHOLIQUE: DES CONNEXIONS ENTRE DES INTELLECTUELS ET LE CAS DU COLLEGE VASCO DA GAMA A LISBONNE, PORTUGAL (DECINNE 1920)}

\section{Résumé}

L'article examine le projet culturel et éducatif de l'école de Lisbonne Vasco da Gama, établissement d'enseignement fondé en 1915, qui visait à instruire et à éduquer leurs élèves sur les bases de l'éducation physique, de la religion et des arts, à la lumière de la doctrine catholique, dans les principes intégralistes et d'une discipline interne rigide. Un journal créé au milieu des années 1920, la source centrale de la recherche, a servi comme l'axe pour définir le projet culturel de l'école et pour exprimer la forme institutionnelle d'un réseau de sujets connectés et actifs dans des temps troublés de la politique portugaise. Basé sur l'histoire des intellectuels et politiques, l'étude examine enfin les connexions entre l'intégralisme lusitanien et le nationalisme catholique brésilien.

Mots-clés: intellectuels, l'éducation catholique, intégralisme lusitani. 


\section{Introdução}

A historiografia, majoritariamente lusitana, apresenta estudos que dedicaram esforços para analisar o alcance político e cultural do Integralismo Lusitano (IL). As obras de Ascensão (1943) e Ferrão (1964) partem de um pressuposto memorialístico e de revisão histórica do movimento. Um conjunto de pesquisas, alicerçado numa crítica historiográfica mais acurada, pode ser localizado, especialmente, em Cruz (1978; 1982 e 1992), Pinto (1982) e Silva (1982). Trabalhos mais recentes de revisão de fontes e ampliação documental, de perspectivas temáticas diferenciadas, foram desenvolvidos, dentre outros, por Quintas (2004), Cordeiro (2009), Carvalho (2012), Cazetta (2015) e Gonçalves (2016).

A gênese do IL, para alguns estudiosos, data de 1913 - ano da criação da revista Alma Portuguesa -, mobilizou, no processo de institucionalização orgânica do movimento, uma intensa produção intelectual, aglutinada, particularmente, em periódicos com circulação nos meios acadêmicos, científicos e culturais lusitanos.

Os intelectuais ${ }^{1}$ atuantes do IL estavam inseridos em espaços diferenciados de agitação e debate político: imprensa, escolas, universidades e na militância católica em geral. Defendiam teses conservadoras e um projeto político antiliberal, a favor da restauração da monarquia em Portugal e atuavam pela "regeneração da alma portuguesa" que, segundo seus protagonistas, perdera sua caracterização original com o avanço das políticas liberais em terras lusitanas. O movimento, em que pese suas diferenças internas, algumas delas já examinadas pela historiografia mais recente, adquiriu organicidade nas circunstâncias históricas agitadas pela consolidação da república portuguesa, a partir de 1910.

Segundo Leão Ramos Ascensão, em obra memorialística publicada no ano de 1943, o IL estruturou-se como movimento em 1916, com a criação da Junta Central do Integralismo Lusitano e a divulgação do seu primeiro manifesto aos portugueses, documento que alertava a nação para o "momento gravíssimo o que estamos vivendo (...) nenhum português pode alegar 0 direito de calar as suas ideias, num comodismo antipatriótico e degradante" (ASCENSÃO, 1943, p. 180). A Junta conclamava o governo republicano a rever sua política de perseguição e exílio das principais lideranças monárquicas e de seus intelectuais atuantes. Juntava-se a essa bandeira a defesa inconteste "em prol da Monarquia orgânica, tradicionalista e anti-parlamentar" (ASCENSÃO, 1943, p. 190). O IL, deliberadamente, criticava o que denominava "o individualismo da ideologia revolucionária" que

Colocou os indivíduos feitos cidadãos eleitores, em face do Estado, sós e isolados, sem os enquadrar em qualquer dos grupos que eles naturalmente deveriam constituir, derivados dos laços de sangue e das afinidades de vizinhança ou de profissão: a Família, a Freguesia ou o Município, a corporação ou o grêmio profissional. O individualismo, que informa os regimes políticos saídos da Revolução francesa, desconheceu esses grupos ou o grêmio profissional. (ASCENSÃO, 1943, p. 110).

\footnotetext{
1 O conceito de intelectual é aqui utilizado a partir das referências de Charle (2003), que propõe uma morfologia das estruturas do campo intelectual, pautada em elementos diacrônicos e sincrônicos específicos, quais sejam: consciência coletiva elitista, urbanização, explosão da imprensa e da edição, concentração geográfica, fenômenos de grupos e redes sociais e espírito de corpo.
} 
Com o intuito de ampliar suas bases de sustentação e ser reconhecido como movimento político ${ }^{2}$, o IL elaborou e divulgou, por meio de diferentes canais de expressão, estatuto próprio e manuais específicos. A Cartilha Monárquica (1916), por exemplo, editada em Lisboa pelo líder integralista Alberto Monsaraz, objetivou popularizar o escopo doutrinário do movimento para atingir um público mais alargado de adeptos.

O panfleto, na epígrafe de abertura, evidenciou a intenção de "condensar em poucas páginas a exposição e defesa das verdades monárquicas, com os argumentos mais acessíveis a todos". No sumário, são arrolados o conjunto temático da obra: conceito de monarquia, seus órgãos e realizações em contraste com os princípios e a doutrina republicana, responsável, segundo a cartilha, pela "desorganização da família, restrições à propriedade, perseguição às crenças, descrédito ao estrangeiro, perturbação da paz pública e renegação da tradição". A conclusão esboçada é ainda mais enfática. Vejamos:

\begin{abstract}
Na Monarquia legisla-se pela Nação. Na República as leis são feitas sempre contra a Nação, contra uma classe ou indivíduo. Na Democracia em vez da Nação aparecem os partidos políticos; em Monarquia a intenção nacional não pode deixar de conduzir a ação dos dirigentes. Em resumo: a Monarquia organiza-se e vive, segundo a Nação; a Democracia desorganiza e dispõe da Nação, segundo os interesses da República. (CARTILHA MONÁRQUICA, 1916, s/p).
\end{abstract}

Outro manual que o IL fez circular em terras lusitanas foi a Cartilha do Operário, publicada em 1919, igualmente editada por Alberto Monsaraz. O conteúdo, de cariz pedagógica, visava esclarecer o mundo operário acerca das mazelas oriundas do liberalismo republicano e do comunismo, recém implantado na Rússia e a necessidade da restauração monárquica, regime fundamentado, segundo a mesma cartilha, na herança do medievalismo católico.

Para o pensamento integralista, o operariado necessitaria absorver graus de consciência e mobilização para atuação no mundo. Neste aspecto, o conteúdo da Cartilha enfatizava a pertinência política da comunidade, da freguesia e da paróquia, estruturas fundantes e necessárias para a implantação de uma saudável vida social, pautada na religião e na educação católica.

Como se vê, o IL não deixou de lado os grupos operários. Não se sabe ao certo quais níveis de apropriação este segmento social absorveu e qual foi o grau de sucesso imposto pela atuação dos integralistas lusitanos junto às classes trabalhadoras. Nos referidos manuais, o IL deixou explícita a defesa de uma monarquia orgânica, sustentada pelos princípios tradicionais do medievo, marcas substantivas da proposta do referido movimento.

O estatuto do IL, principal documento do órgão e publicado em 1917, foi redigido por uma plêiade intelectual que gozava, à época, de reconhecimento junto aos principais órgãos da cultura lusitana de perfil conservador: Xavier Cordeiro, António Sardinha, Alberto Monsaraz, Hipólito Raposo, João do Amaral, Luiz de Almeida Braga, Rui Enes Ulrich e Pequito Rebello. Intelectuais atuantes e protagonistas dos principais veículos de divulgação da doutrina integralista lusitana, dos quais destacaram-se: Alma Portuguesa, Nação

\footnotetext{
2 O conceito de político está em consonância com os estudos de Pierre Rosanvallon. Para o autor, "falar substantivamente do político, qualifico desse modo, tanto uma modalidade de existência da vida comum, quanto uma forma de ação coletiva que se distingue implicitamente do exercício da política". (ROSANVALLON, 2010, p. 73).
} 
Portuguesa, Integralismo Lusitano - Estudos Portugueses, Portugália, Gil Vicente, Vasco da Gama, Política, entre outros.

Alcançar os estudantes secundaristas e universitários era outra meta do IL. A revista Política, que circulou por Lisboa entre abril de 1929 e março de 1931, era editada pelo Órgão da Junta Escolar de Lisboa do Integralismo Lusitano e, nesses anos, publicou variada discussão sobre o papel e a função da juventude escolar e acadêmica na luta pela regeneração da alma portuguesa, por meio da restauração monárquica, seguindo os preceitos doutrinários do IL.

Da mesma forma, era preciso, segundo os estatutos e veículos de divulgação doutrinária do órgão, atingir o público juvenil em fase de formação cognitiva, afetiva, moral e religiosa. Estágios nevrálgicos, a infância e a adolescência tornaram-se, para determinados setores da pedagogia do IL, fases cronológicas estratégicas. Para tanto, um cuidado especial e dirigido.

A hipótese que rege a presente investigação, elege o educandário particular Vasco da Gama de Lisboa e sua revista de mesmo nome, como a instituição e o veículo de educação juvenil conectadas com os princípios doutrinários do IL.

O presente artigo está estruturado em duas partes. Na primeira, sistematiza-se a apresentação analítica das fontes e as problematizações que nortearam o estudo em epígrafe, particularmente as que versam sobre as conexões entre o IL e o campo escolar. A segunda parte, examina o projeto cultural e pedagógico do colégio lisboeta Vasco da Gama, instituição de ensino fundada em 1915, que pretendeu instruir e educar seus alunos sob as bases da educação física, da religião e das artes, à luz da doutrina católica, dos princípios integralistas e de uma rígida disciplina interna.

\section{O IL e a educação escolar: aproximações}

Examinar o IL e suas repercussões no campo escolar é tarefa desafiadora. Para tanto, merecem ser verificadas, a princípio, algumas aproximações e conjecturas que, detectadas no cruzamento de algumas fontes pesquisadas, conduziram-nos a elaborar uma tese sobre a atuação de intelectuais vinculados ao espectro ideológico do IL no âmbito da escola lusitana, nomeadamente as instituições de ensino católicas.

Não foi possível, até o presente momento, proceder um levantamento minucioso das escolas católicas portuguesas entre as décadas de 1910 e 1920, período central da atuação dos intelectuais integralistas, especialmente em Lisboa, capital lusitana de expressão e circulação das principais publicações do grupo. Porém, a pesquisa organizada por Simpson (2014) fornece dados relevantes sobre a situação da Igreja católica portuguesa na década de 1920 e princípios dos anos de 1930, fase nevrálgica de atuação do IL em consonância com a emergência do salazarismo em terras lusitanas.

Para Simpson (2014), os anos de 1928 a 1933 foram decisivos para a implantação do regime liderado por Oliveira Salazar. Num movimento complexo de convergências e disputas, os grupos católicos portugueses atuaram, cada qual ao seu modo, em um universo político de interesses corporativos, em que pese a perseguição organizada por grupos republicanos contrários à hegemonia do catolicismo e suas vertentes no país.

A Igreja, para o referido autor, conheceu, após a proclamação da república em 1910, momentos de crise, reação e rearmamento político. Entre 1918 e 1926, com o 
sidonismo e a chamada "Nova República Velha"3, os católicos conheceram um período de reagrupamento ativo, com a criação de novos seminários, um lento regresso de congregações religiosas exiladas, um relativo crescimento das ordenações sacerdotais e o sucesso atribuído ao culto à Nossa Senhora de Fátima, entre outras medidas. Porém, o destaque ficou à capacidade de articulação política do laicato militante que, em associações e órgãos específicos, atuou em defesa do legado doutrinário católico.

Exemplos foram o Centro Acadêmico de Democracia Cristã, refundado em 1911 por uma nova geração de jovens de Coimbra (Salazar e Manoel Cerejeira, por exemplo) e o Centro Católico Português, criado em 1915, simpático e, por vezes alinhado, às tendências monárquicas e antiliberais aglutinadas no IL. (SIMPSON, 2014).

Nesse cenário, segundo a hipótese originalmente apontada na presente investigação, integrou-se o colégio Vasco da Gama, que se apresentou à sociedade lusitana como uma alternativa privada e católica de formação intelectual, moral e religiosa das novas elites de Portugal, numa conjuntura marcada por defecções de todos os lados, golpes e contra- golpes, ditadura e ascensão do salazarismo.

Pesquisa que realizamos sobre as conexões entre o IL e o nacionalismo católico brasileiro (GONÇALVES, 2016)4, verificou, nos periódicos de cariz integralista, especialmente na revista Nação Portuguesa ${ }^{5}$, reiterada propaganda do colégio Vasco da Gama, fundado em 1915 e dirigido por Monsenhor António Manuel da Silva Pinto Abreu (1866-1948) ${ }^{6}$ e Luiz Gonzaga da Silva Pinto Abreu .

Três fontes foram centrais para o presente estudo: uma publicação institucional de divulgação do colégio, lançada em 1931; o regulamento disciplinar e instruções regulamentares para os prefeitos (chefes de disciplina escolar), de 1928 e, por fim, o periódico Vasco da Gama, revista denominada de "Pedagogia e Cultura", da própria instituição, que circulou entre os anos de 1925 e 1927, veículo dirigido por Fidelino de Figueiredo $^{8}$, simpático às ideias monárquicas, pois simultaneamente à direção do referido periódico, foi editor-chefe da revista de cultura Portugália, propriedade do Conselho Diretor Central das Juventudes Monárquicas Conservadoras. ${ }^{9}$

\section{A aproximação do IL ao campo escolar remonta sua gênese como movimento}

\footnotetext{
3 Informações sobre o período histórico em questão, consultar Cruz (1992) e Rezola (2008).

${ }^{4}$ Pesquisa desenvolvida no Instituto de Educação da Universidade de Lisboa, entre os meses de novembro de 2014 e março de 2015, com apoio da Fapesp e sob supervisão do Prof. Dr. Justino Pereira de Magalhães.

${ }^{5}$ Cordeiro (2009) examinou os dois primeiros anos de circulação desse periódico integralista, de 1914 a 1916, caracterizados como a primeira fase de sua existência.

6 Pinto Abreu atuou junto à infância pobre, em aliança com as Forças Armadas, que o assessorava na instrução militar e no fornecimento de material. Chegou a abrir um educandário que foi fechado por ocasião da proclamação da república portuguesa em 1910. Informações adicionais sobre a trajetória desse prelado, consultar Grande Enciclopédia Portuguesa e Brasileira, s/d, vol. 21. Agradecemos o Prof. Dr. Justino Pereira de Magalhães, do Instituto de Educação da Universidade de Lisboa, pelas informações cedidas.

7 Não localizamos dados sobre Luiz Gonzaga P. Abreu, irmão do monsenhor António Manuel. Conforme indícios verificados na revista Vasco da Gama, ambos seguiram juntos na criação e direção do colégio, em igual posição de destaque.

8 Sobre a biografia de Figueiredo, consultar Carneiro (2003). Curioso destacar que o vínculo deste intelectual com a causa monárquica não é referido no verbete correspondente, nem mesmo a sua participação, numa tentativa de golpe, em agosto de1927, contra a ditadura recém instalada em Portugal. Com ele estava Filomeno da Câmara. A iniciativa frustrada ficou conhecida na historiografia lusitana como o "Golpe dos Fifis", em alusão aos nomes dos dois líderes. (MENEZES, 2015, p. 72 e nota n. 60, p. 672).

${ }^{9}$ As fontes citadas pertencem ao acervo da Biblioteca Nacional de Portugal e foram pesquisadas na ocasião da visita técnica que realizamos no mês de outubro de 2015, sob supervisão do Prof. Dr. Justino Pereira de Magalhães.
} 
político. O primeiro periódico lançado pelo movimento integralista - Alma Portuguesa ${ }^{10} \_$ apresentava-se como uma revista de Filosofia, Literatura, Arte, Sociologia, Educação, Instrução e Atualidades. Seu primeiro número foi publicado em Louvain, Bélgica, por intelectuais emigrados e defensores da ideologia monárquica. O corpo editorial da revista era construído por Gusmão Araujo, Ramos Ribeiro, Rolão Preto, D. António Alves Pereira e Ascenso de Siqueira.

No segundo número (maio de 1913), a instrução recebeu uma atenção específica da revista, no artigo assinado por João da Cruz intitulado Instrução e educação. O autor atacou a ideologia liberal, defendendo a tese da prioridade da "formação do caráter", bandeira histórica do catolicismo, em detrimento da "instrução pura e simples". Além disso, aponta a "educação da vontade" e a "cultura dos sentimentos" como caminhos seguros para a formação integral dos sujeitos.

Cruz rebate o predomínio da orientação liberal na filosofia orientadora das políticas e métodos educacionais em voga, todas elas inspiradas, segundo ele, nos preceitos da tradição francesa, fundamentados em diferentes tendências do lluminismo. Um trecho, especificamente, é esclarecedor, pois apresenta a intenção em debater um projeto educacional que promovesse a articulação entre a formação individual, do caráter, da educação física, moral e religiosa das novas gerações lusitanas. Note-se, de relance, uma referência a princípios pedagógicos modernos, sem perder a base da tradição:

\begin{abstract}
Orientem-se as escolas de forma a robustecer a iniciativa individual; a preparar homens armados para a luta da vida, com a consciência dos seus direitos e dos seus deveres, fisicamente fortes, solidamente instruídos, certos do destino superior que lhes assegura a religião sem a qual não há moral, como demonstra Brunetière, um dos mais altos espíritos da França Republicana. (CRUZ, In: Alma Portuguesa, série I, n. 1, mai. 1913, p. 25)
\end{abstract}

Nação Portuguesa ${ }^{11}$, o mais importante veículo de divulgação do IL, manteve conexões com o campo escolar. No primeiro número da revista foi publicado "o plano completo e sistemático de ação e estudo que constituirá toda razão de ser de uma orientação política nacional que já agora podemos denominar Integralismo Lusitano" (NAÇÃO PORTUGUESA, ano I, abr. 1914, p. 4). Constava do plano ações diretas relacionadas ao âmbito da escola e da formação da juventude: eleição de representantes escolares para liderar a militância, defesa da escola e universidade livres e, por fim, a criação de instituições de formação industrial regionalizadas.

Outras pistas podem ser demarcadas. A sessão Publicações Recebidas, por exemplo, anunciou o recebimento da revista Escola, veículo mensal de pedagogia do Rio de Janeiro ${ }^{12}$. Apoiava as iniciativas das Juntas Escolares do IL em diferentes municípios de Portugal $^{13}$. e divulgava eventos da área, como o II Congresso Pedagógico do Ensino Secundário Oficial, realizado em Viseu, no ano de $1925^{14}$.

\footnotetext{
10 De curta duração e publicada na França por monarquistas exilados, a revista denominava-se "Órgão do Integralismo Lusitano". Sua máxima era: "A monarquia é a restauração da inteligência". Em 1914, foi substituída pela Nação Portuguesa, periódico lisboeta de divulgação integralista.

${ }^{11}$ Circulou em três fases distintas: 1914-1916; 1922-1924 e 1924-1928. Seus principais editores foram Alberto Monsarraz e António Sardinha. Para a primeira fase da revista, consultar Cordeiro (2009).

12 Cf. Nação Portuguesa, 3a série, n. 4, 1925, p. LXXXVII.

13 Cf. Nação Portuguesa,3a série, n. 7-8, 1925, p. CXXVIII-CXXIX.

14 Cf. Nação Portuguesa, Série V, n. 1, Tomo I, 1928, p. 85-86.
} 
O esboço acima delineado, mesmo que sumário, aponta elementos que refletem as intencionalidades doutrinárias do IL e a preocupação dos seus intelectuais e lideranças com o campo da instrução básica. A escola, desta perspectiva, era a instituição educacional privilegiada, com potencial formativo e de inserção sincrônica, tendo em vista a institucionalização diacrônica de modelos pedagógicos e de formação humana, segundo a ótica desse espectro ideológico ${ }^{15}$.

\section{O colégio Vasco da Gama: "saúde do espírito, vigor do corpo e da vontade"}

A décima edição (1930) da revista Política ${ }^{16}$, órgão da Junta Escolar de Lisboa do IL, dedicou integralmente sua pauta às homenagens a António Sardinha, um dos principais líderes do IL, falecido alguns anos antes. O periódico reuniu o conjunto emblemático de intelectuais para, em efeméride, exaltar a inteligência e a liderança de Sardinha em Portugal. Nessa edição, o colégio Vasco da Gama foi divulgado entre as instituições apoiadoras da revista e exemplo de educandário:

Colégio Vasco da Gama. Modelar estabelecimento de educação e ensino. Rivalizando com os melhores do estrangeiro. Instrução Primária, secundária, industrial e agrícola. Internato, semi-internato e externato. Edifício escolar expressamente construído. Campos de jogos, ginásio, patinagem, piscina, equitação e cinematógrafo. Confiai-Ihe a educação dos vossos filhos. (POLÍTICA, ano I, n. 10, 1930, p. 80).

O conteúdo aludido na seção de propaganda da revista supracitada, circulou em outros periódicos de cariz integralista, com destaque à Nação Portuguesa. Lideranças políticas e religiosas de Portugal, ligadas ao espectro ideológico do nacionalismo católico português e do IL participaram de eventos e cerimônias promovidas pelo colégio, tais como: Gonçalves Cerejeira, nomeado Patriarca de Lisboa em 1929, Hipólito Raposo, liderança integralista e Martinho Nobre de Melo, ex-ministro de Estado, embaixador de Portugal no Brasil entre os anos de 1932-1946 e um dos homens de confiança de Salazar. ${ }^{17}$

A ligação do colégio com Fidelino de Figueiredo, lembrada anteriormente, merece uma análise pontual. Editor-chefe da revista de divulgação da escola, Figueiredo transitou em diferentes espaços de cultura e da politica portuguesa, nomeadamente em divisões específicas do Ministério da Instrução Pública, no período da presidência de Sidónio Pais, em fins da década de 1910.

As preocupações com questão educacionais estiveram presentes desde a gênese da sua carreira intelectual. $O$ título da tese de licenciatura $A$ educação da abstraccção comprova sua inicial tendência em examinar tal objeto. Dado não menos importante referese à prioridade dada ao ensino secundário, com ênfase na História e na Filosofia. Em meio à crise política de 1910 que abalou Portugal, Figueiredo pronunciou a conferência $A$

\footnotetext{
${ }^{15}$ Magalhães (2016) analisa o papel dos intelectuais e as relações cognitivas com o campo da educação. Aponta a intrínseca conexão entre o ofício do pensar e a institucionalização dos processos de inserção sincrônica dos agentes da educação (intelectuais, no caso), por meio do que o autor denomina "escrita pedagógica e escrita didática". Os regulamentos e manuais escolares, por exemplo, podem ser analisados a partir desse prisma. Essa é abordagem que fundamenta a análise das fontes aqui selecionadas.

16 Dirigida por A.de Mendonça Dias, Política circulou entre abril de 1929 e março de 1931. Disponível em: $<$ hemerotecadigital.cm-lisboa.pt/Periodicos/Politica_OrgaodaJunta/Politica_OrgaodaJunta.htm>. Acesso em: 21 mar. 2016.

17 Cf. Vasco da Gama, vol. I, jan./mar. 1926, n. 2, p. 113-115 e ano II, n. 6, jan./mar. 1926-1927, p. 56-62.
} 
educação na futura democracia portuguesa, na Academia de Estudos Livres de Lisboa, ocasião que explicitou sua concepção de educação que, segundo ele, deveria superar a "mera instrução", defendendo um "ensino educativo". (CORDEIRO, 2003, p. 341).

Esse ardor pela "causa da educação" e de um "ensino educativo", pautado num espírito militante junto aos quadros nacionalistas e integralistas de cariz católico, ganhou materialidade, dentre outras ações, na confecção e direção da revista Vasco da Gama, periódico oficial da institução de ensino em tela.

Como dito anteriormente, os responsáveis pela pauta doutrinária da escola, lançaram, em 1931, um material ${ }^{18}$ de divulgação com referências ao corpus pedogógico da instituição. Com o objetivo de ampliar a clientela e concorrer no campo do ensino particular lusitano, os diretores apresentaram o que entendiam ser "incontestavelmente o primeiro do País", pois ofereciam os "melhores resultados, um corpo docente selecionado e uma disciplina inteligente". A Revista apresenta, ainda, o desenho do prédio, plantas, interiores, dentre outros elementos propagandísticos. Pelo conteúdo introdutório, atendiam uma clientela privilegiada social e economicamente e localizado "num dos bairros mais saudáveis da cidade". (REVISTA, 1931, p. 3).

A perspectiva de "formação integral" define o escopo da proposta pedagógica do colégio, na linha do "ensino educativo" de Fidelino de Figueiredo e da histórica posição católica sobre a educação das almas. O objetivo central da instituição era

restabecer na mocidade portuguesa a saúde do espírito, o vigor do corpo e da vontade, a preparação intelectual e a fé com que todas as sociedades sãs constituem as suas aristocracias do caráter. (REVISTA, 1931, p. 3).

Formar uma sã aristocracia, pautada nos princípios católicos, garantir a sáude física e moral dos seus alunos, privilegiando o "vigor físico da mocidade" (ibidem, p. 4), estavam dentre os objetivos pontuais da instituição. Uma rígida disciplina norteava os estatutos da escola e, pela persuasão, buscavam a apropriação de hábitos, particularmente o da ordem.

O colégio oferecia uma variedade de cursos, pois pretendia a "instrução e a educação moral, intelectual, física e artística" dos seus alunos (ibidem, p. 6). No campo da educação moral, preleções cívicas e cursos de apologética, estavam indicados no organograma institucional. A educação intelectual era realizada, segundo o conteúdo da Revista, desde as classes infantis ao término do secundário, composto pelos seguintes cursos: Liceau, Comercial, Agrícola e, ainda, os cursos Vasco da Gama (para admissão em faculdades lusitanas) e o Pré-Universitário, preparativo para o ensino superior no estrangeiro.

Uma rígida seleção de docentes e criteriosa escolha do material didático definiam o perfil didático-pedagógico da instituição. Para os ideólogos do colégio, ao professor cabia "moldar, instruir e educar" o alunado (ibidem, p. 12). A prática da educação física era desenvolvida por meio da esgrima, natação, equitação e volteio, patinagem, tenis, basquete e futebol.

Um "Livro de Ouro" fecha a Revista, assinado por lideranças políticas, culturais e religiosas, com destaque ao general Carmona $^{19}$ e ao Cardeal Patriarca de Lisboa,

18 Intitulado Colégio Vasco da Gama, o referido material será doravante denominado Revista.

19 À época presidente de Portugal, tendo como ministro das Finanças António Salazar. Disponível em: <http://www.historiadeportugal.info/oscar-carmona/>. Acesso em: 25 jan. 2017. 
Gonçalves Cerejeira, ambos próximos a Salazar e apoiadores incontestes da linha política ditatorial, consubstanciada, alguns anos mais tarde, no Estado Novo. As assinaturas de apoio ao colégio datam da década de 1920, especificamente no seu final, conjuntura favorável aos grupos conservadores lusitanos, nomeadamente setores católicos e integralistas.

Para a manutenção da ordem e disciplina, a direção do colégio sistematizou um regulamento interno ${ }^{20}$, direcionado à orientação dos prefeitos ${ }^{21}$, "pedras angulares, sobre que assenta a disciplina geral do estabelecimento, e portanto devem exercer sobre os alunos uma ação contínua e eficaz". (REGULAMENTO, 1928, p. 8).

Aos alunos era reservado um ordenamento disciplinar de 28 artigos. $O$ regulamento expressava a concepção pedagógica e de formação do caráter do alunado do colégio: silêncio, pontualidade, espírito de poupança, critérios na leitura de livros e revistas, asseio, civilidade, ordem e disciplina. Assim, os diretores e docentes do colégio buscaram efetivar uma proposta pdagógica, nascida no bojo do antirrepublicanismo lusitano. ${ }^{22}$

\section{Considerações finais}

Pátria, religião e família aparecem de forma reiterada no conjunto documental pesquisado sobre a instituição em tela. A presença de mentores e líderanças católicas vale lembrar que um dos fundadores do colégio pertencia à hierarquia eclesiática configurava a coloração didático-pedaógica da escola e que se expressava na regulamentação disciplinar do colégio.

$\mathrm{O}$ apoio recebido pelas autoridades políticas estatais, evidenciado nas visitas divulgadas pela revista oficial da instituição e pelas declarações de apoio de membros do governo e adeptos do IL, localizadas nas fontes aqui examinadas, indicam uma aproximação estratégica dessa iniciativa particular de ensino aos princípios e bandeiras ideológicas dos grupos antirrepublicanos lusitanos.

A criação do colégio, em 1915, cinco anos após a proclamação da república portuguesa, fortaleceu, em certa medida, a reação de grupos católicos no setor do ensino, nomeadamente o secundário, estágio promissor do ponto de vista da formaçao do caráter. O rearmamento católico passava, necessariamente, pelo campo edcacional.

$\mathrm{Na}$ conjuntura imediatamente posterior, de gênese do salazarismo, em finais da década de 1920, os diretores do colégio, por meio da publicação da Revista e do Regulamento, fontes aqui examinadas, evidenciaram a tentativa mais sistemática dos mentores do Vasco da Gama em disputar o espaço para atuar na formação da juventude portuguesa, particularmente aquela vinculada aos setores privilegiados da sociedade lusitana. O apoio, neste caso, dos veículos de divulgação do IL, da hierarquia e do laicato católicos, bem como de representantes de órgãos estatais estratégicos, serviram de base para que a proposta institucional do colégio fosse propagada em Portugal e no exterior.

20 Doravante denominado Regulamento.

21 Chefes de disciplina e responsáveis pelo cumprimento das regras internas do colégio.

22 Não localizamos dados mais objetivos sobre fluxo de matrículas e outros dados internos ao colégio, por exemplo. Uma próxima visita técnica aos arquivos lusitanos poderá contribuir para a ampliarmos o entendimento da proposta institucional em tela. 


\section{Periódicos, revistas e outras publicações ${ }^{23}$}

Vasco da Gama

Alma Portuguesa

Nação Portuguesa

Política

Colégio Vasco da Gama

Regulamento disciplinar e Instruções regulamentares para os prefeitos

\section{Referências}

ASCENSÃO, Leão Ramos. O Integralismo Lusitano. Gama: Lisboa, 1943.

CARVALHO, Paulo Archer de. Integralismo Lusitano: reação, recristianização, retorno. Locus, Revista de História, Juiz de Fora, v. 18, n. 1, p. 13-31, 2012.

CAZETTA, Felipe Azevedo. Integralismo Lusitano e Nacional Sindicalismo: movimentos de extrema-direita em contato com ditaduras em Portugal. Cadernos de História, Belo Horizonte, v. 16, n. 24, p. 30-50, 2015.

CHARLE, Christophe O nascimento dos intelectuais contemporâneos (1860-1898). Trad. Maria Helena Camara Bastos. História da Educação, v. 7, n. 14, p. 141-156, 2003.

CARNEIRO, Mário. Figueiredo Fidelino. In: NÓVOA, António (Org.). Dicionário de educadores portugueses. Porto: ASA Editores, S.A., 2003, p. 341.

CORDEIRO, José Manuel. Nação Portuguesa (1914-1916) - Que Integralismo Lusitano? Cultura, Revista de História e Cultura das Ideias, Centro de História d'Aquém e d'AlémMar, Lisboa, Portugal, v. 26, p. 139-154, 2009.

CRUZ, Manuel Braga da. As origens da democracia cristã em Portugal e o salazarismo. Análise Social, v. XIV (54), p. 265-278, 1978-2․

. O Estado Novo e a Igreja Católica. In: MARQUES, A. H. de Oliveira; SERRÃO, Joel. Nova História de Portugal, v. 12. Lisboa: Editorial Presença, 1992.

. O integralismo lusitano nas origens do salazarismo. Análise Social, v. XVIII (70), p. 137-182, 1982-1․

FERRÃO, Carlos. O Integralismo e a República. Autópsia de um mito. Lisboa: Inquérito Editorial O Século, 1964-1965, 2 vols., 1964.

GONÇALVES, Mauro Castilho. Integralismo lusitano, nacionalismo católico e educação: conexões entre intelectuais (1913-1934). NUPEM, Campo Mourão, v. 8, n. 14, p. 99-116, jan./jun. 2016.

MAGALHÃES, Justino Pereira de. Intelectuais e história da educação em Portugal e Brasil. Cadernos de História da Educação, Uberlândia, UFU, v. 15, n. 1, p. 299-322, jan./abr. 2016.

MENESES, Filipe Ribeiro de. Salazar. biografia definitiva. São Paulo: Leya, 2011.

MONSARAZ, Alberto et al. Estatuto do Integralismo Lusitano. Lisboa: A Monarquia ,1917.

MONSARAZ, Alberto. Cartilha do Operário. Lisboa: Tipografia Soares \& Guedes Ltda., 1919.

${ }^{23}$ Acervo da Biblioteca Nacional de Portugal. 
Cartilha Monárquica. Lisboa: Anuário Comercial, 1916.

PINTO, Antonio Costa. A formação do Integralismo Lusitano (1907-1917). Análise Social, Lisboa, v. XVIII, p. 1409-1419, 1982.

QUINTAS, José Manuel Alves. Filhos de Ramires. As origens do Integralismo Lusitano.

Lisboa: Nova Ática, 2004.

REZOLA, Maria Inácia. A Igreja Católica portuguesa e a consolidação do salazarismo. In: MARTINHO, Francisco Carlos Palomanes; PINTO, António Costa. O corporativismo em português: estado, política e sociedade no salazarismo e no varguismo. Rio de Janeiro: Civilização Brasileira, 2007.

ROSANVALLON, Pierre. Por uma história do político. São Paulo: Alameda, 2010.

SILVA, Armando Barreiros Malheiro da. Leonardo Coimbra e o Integralismo Lusitano.

Bracara Augusta, Braga, Câmara Municipal, v. XXXVI, n. 81-82, p. 433-489, jan./jul. 1982.

SIMPSON, Duncan. A igreja católica e o Estado Novo salazarista. Lisboa, Portugal:

Edições 70, 2014.

MAURO CASTILHO GONÇALVES é professor do Programa de Estudos Pós-Graduados em Educação: História, Política, Sociedade da Pontifícia Universidade Católica de São Paulo e da Universidade de Taubaté, SP. Doutor em Educação: História, Política, Sociedade pela PUC-SP.

Endereço: Rua Brigadeiro Galvão, 436, ap. 147 - 01151-000 - São Paulo/SP - Brasil.

E-mail: mauro_castilho@uol.com.br

Recebido em 13 de fevereiro de 2017.

Aceito em 28 de março de 2017. 